\title{
MEPHEDRONE CONSUMPTION IN MADEIRA ISLAND \\ A PUBLIC HEALTH PROBLEM
}

C. Spínola ${ }^{1}$, L. Santana ${ }^{1}$, J. Gago ${ }^{1,2}$, L. Santos ${ }^{3}$, D. Neto ${ }^{3}$.

${ }^{1}$ Centro Hospitalar Lisboa Ocidental, Psychiatry and Mental Health, Lisbon, Portugal.

${ }^{3}$ NOVA Medical School, Lisbon, Portugal

${ }^{3}$ Serviço de Saúde da Região Autónoma da Madeira, Psychiatry, Funchal, Portugal.

\section{Objectives}

To analyse the forced emergency department psychiatric evaluations due to drug induced disorders.

\section{Materials and methods}

We conducted a two-year retrospective observational study. Patients aged 18 and above, admitted to the emergency department between January 2017 and December 2018 due to drug induced psychosis were considered. Clinical records regarding forced emergency department admissions were analysed.
Background and aims

\begin{abstract}
Synthetic cathinones, frequently known as "bath salts", have emerged as a popular designer drug of abuse causing significant hazardous effects on mental and physical health. Cathinones are structurally related to amphetamines, and their mechanisms of action are thought to be similar. Chronic amphetamine use is known to be neurotoxic to dopaminergic neurons, resulting in long-term reductions in brain dopamine concentrations in chronic users. ${ }^{1}$ The toxicity of synthetic cathinones includes significant sympathomimetic effects, as well as psychosis, agitation, aggression, and sometimes violent and bizarre behavior. ${ }^{2}$

After significant number of deaths and disturbances registered in 2012, selling all types of designer drugs (known and unknown substances) was made illegal in Portugal. Mephedrone was the main cause of concern.
\end{abstract}

\section{Results}

We identified a total of $\mathbf{1 4 2}$ patients with the diagnosis of Drug Induced Psychosis, mean age of 35 years ( $\mathrm{sd}=9.6$ ), 95\% male, $77 \%$ single, $48 \%$ unemployed, $2 \%$ retired; $71 \%$ with $4-9$ years of education.

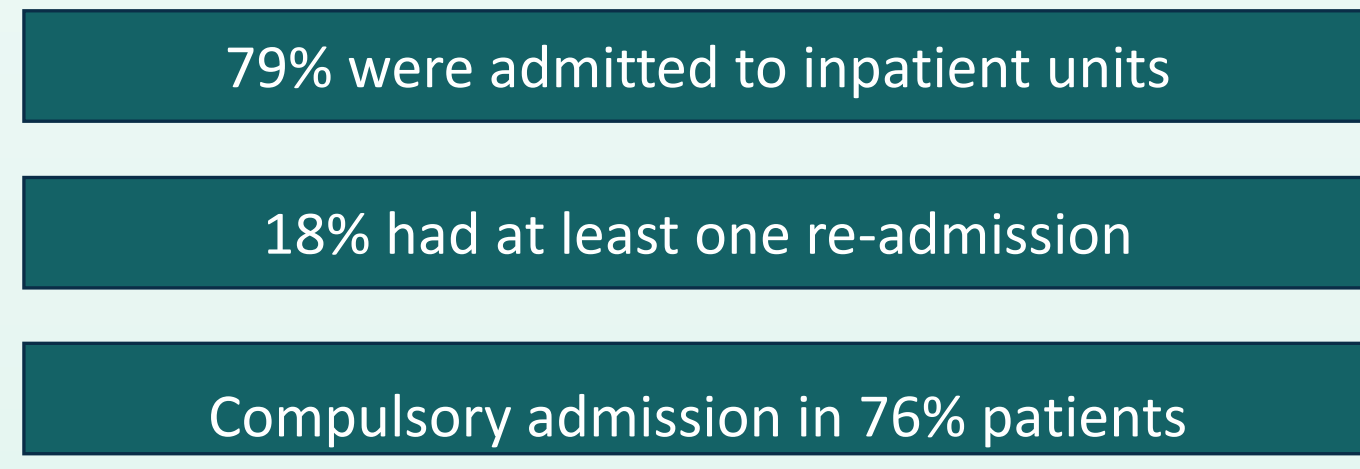

Drug consumption

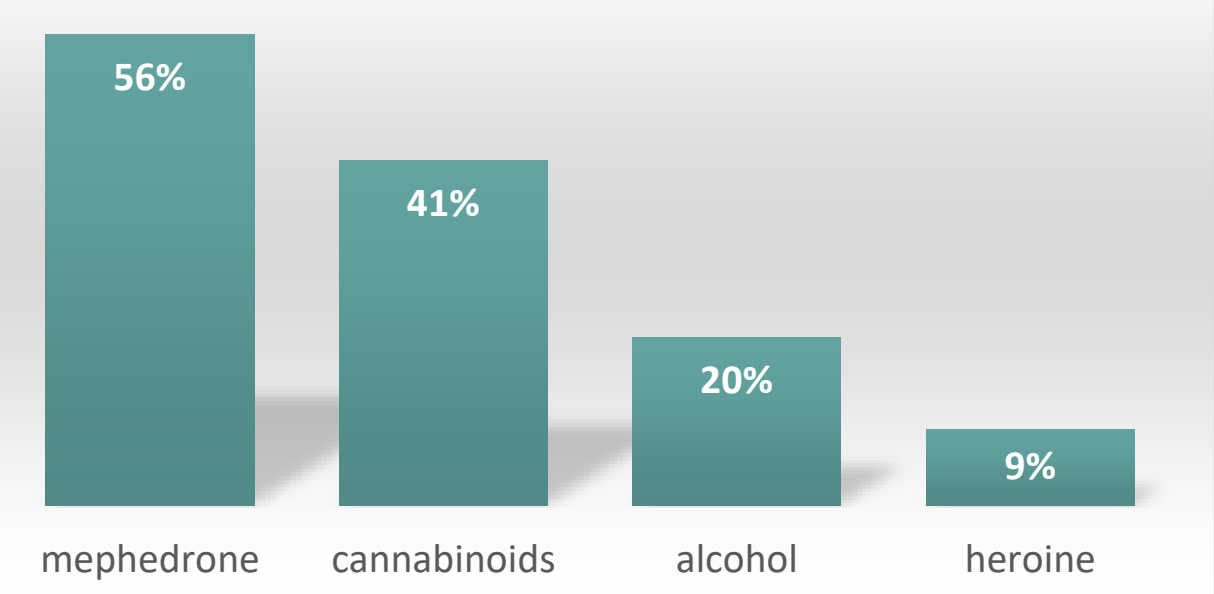

$35 \%$ consumed mephedrone and other substances

\section{Mephedrone Induced Psychosis Group}

77\% patients were admitted to inpatient units (73\% compulsory admissions)
Acts of violence being registered in $84 \%$ of patients

\begin{abstract}
As seen in our sample, the literature suggests that co-ingestion of other drugs of abuse and alcohol frequently accompanies synthetic cathinone use. ${ }^{3}$

It has already been proved that mephedrone has potential to induce acute aggressive behaviour and can increase the risk of self harm or accidental harm. ${ }^{4}$
\end{abstract}

These results are substantially different from those of the Portuguese National Authority for Treatment and Prevention of Drug Induced Disorders, evidencing a regional problem. In our sample we found that $18 \%$ of patients had at least one readmission, suggesting that a significant number do not fully recover after the first episode (showing residual symptoms beyond acute phase) or that patients probably maintain the use of these substances after discharge.

Conclusions

References
Our data suggest a different profile of addictive behaviour in this region with a significant amount of patients being admitted due to mephedrone induced psychosis. The burden of this observation calls for an urgent development and implementation of Public Health measures in order to prevent consumption and detect signs of early onset psychosis.

1.Ellison G. Neural degeneration following chronic stimulant abuse reveals a weak link in brain, fasciculus retroflexus, implying the loss of forebrain control circuitry. Eur Neuropsychopharmacol. 2002;12(4):287-297

2.James D, Adams RD, Spears R, et al. Clinical characteristics of mephedrone toxicity reported to the UK National Poisons Information Service. Emerg Med J. 2011;28(8):686-689

3. Spiller HA, Ryan ML, Weston RG, Jansen J. Clinical experience with and analytical confrmation of "bath salts" and "legal highs" (synthetic cathinones) in the United States. Clin Toxicol. 2011;49(6):499-505

4. McGraw M, McGraw L. Bath salts: not as harmless as they sound. J Emerg Nursing. 2012;38:582-588. 